\title{
I. APPROACHING CONTEMPORARY PSYCHOANALYTIC RESEARCH
}

\author{
PATRIZIA GIAMPIERI-DEUTSCH
}

\begin{abstract}
"[...] the intellect and the mind are objects for scientific research in exactly the same way as any non-human things. Psychoanalysis has a special right to speak for the scientific Weltanschauung at this point [...]" The question of a Weltanschaunng, $35^{\text {th }}$ Lesson of New Introductory Lectures on Psycho-Analysis (Freud 1933 a [1932], p. 159).
\end{abstract}

In the present volume current research in psychoanalysis interfaces with research in philosophy of mind and experimental sciences, especially in cognitive neuroscience. The "common ground" of these collected essays is their deeply shared interest in an emerging science of the mind. The book contains a collection of original papers categorized under three headings: Section I is devoted to the recent research on conscious and unconscious processes in psychoanalysis, philosophy of mind and experimental sciences; Section II provides an overview of current interdisciplinary research in neuroscience and psychoanalysis and Section III explores empirical research trends in contemporary psychoanalysis. Finally, some articles in this volume can also be understood as an attempt to establish a foundation of empirical and experimental research in psychoanalysis on the quite modern epistemological approach of Freud himself.

\section{PSYCHOANALYSIS, PHILOSOPHY OF MIND AND EXPERIMENTAL SCIENCES}

\section{1. CURRENT ANALYTIC PHILOSOPHY OF MIND AND COGNITIVE NEUROSCIENCE}

Current analytic philosophy of mind attempts to outline a theory of mind as psychoanalysis did in the past and is now doing again, but despite the seeming similarity of their aims a co-operation of the two is very challenging. 
Up until now attempts to bring psychoanalysis and philosophy together have generally failed.

Philosophers who praised the particular knowledge of psychoanalysis, for example Ricœur and Habermas, managed rather to put psychoanalysis outside of the empirical sciences, whereas philosophers of science - including Ernest Nagel, Sir Karl Popper, Adolf Grünbaum ${ }^{1}$ - did not regard it as a science at all.

Psychoanalysis is thankfully still alive, it has survived those attempts to distance it from empirical sciences quite successfully - even though in some cases unwittingly -, and it is indeed philosophy which has become increasingly threatened with being banished to so called "reservations".

A remnant of such alliances with hermeneutics or such encounters with philosophy of science has resulted in the fact that psychoanalysis does not really see itself as a science.

Current analytic philosophy of mind is no longer an "armchair philosophy" or an "armchair psychology", but it now tries to integrate the outcomes of experimental sciences as neuroscience and cognitive science, as current psychoanalysis does by updating its metapsychology.

Analytic philosophy was a philosophy of language that seriously questioned the possibility of a suitable theory of mind and even derided it as a "philosophy of ghosts". Its goal was to overcome the ambitious philosophy as metaphysics through the unpretentious analysis of language.

This modest aim became a quite pretentious one: philosophy could only analyze sentences, but at last it could analyze every sentence including the sentences of experimental sciences - and decide if they are meaningful.

Analytic philosophy now raises again the old metaphysical questions (for example, ontological questions about main topics such as

${ }^{1}$ According to Ernest Nagel (Nagel 1959) psychoanalysis is not a science because it does not study an observable behavior, as a scientific psychology has to do, and it has no operational definitions, but it is concerned with "metaphoric" entities as so called mental phenomena are; according to Popper (Popper 1962) psychoanalysis is not a science because its sentences are not falsifyable as sentences of the other sciences indeed are; according to Grünbaum (Grünbaum 1984, 1991, 1993, 2002) - the most accurate of the three - the clinical theory of psychoanalysis is not yet a scientific one because of the lack of empirical research proving that psychoanalysis heals. 
"What is consciousness? What is a representation? What is an affect?" and so on) but it requires provisional empirical answers, answers that only experimental sciences can provide.

Most analytic philosophers and also those I am interested in assume a naturalistic approach. The philosophical approach of naturalism is that experimental sciences are the paradigm of knowledge: to the question "What do we know about something?" naturalism tells us that our knowledge about something comes from the results of experimental sciences; and to the question "How do we get reliable knowledge?" naturalism answers that the proceedings are those of experimental sciences.

I would like to give a brief insight into this trend within the philosophy of mind.

In the current philosophy of mind the articles and books of naturalistic philosophers such as Ned Block (Block 1995), Owen Flanagan (Flanagan 1992; Güzeldere, Flanagan \& Hardcastle 2000), John Searle (Searle 1992), Fred Dretske (Dretske 1995), David Chalmers (Chalmers 1996) attempt to answer, for example, what consciousness is through the interpretation of neuropsychological syndromes.

Some naturalistic philosophers have considered neuropsychological studies of brain-damaged patients with specific perceptual and cognitive deficits who have access to knowledge of which they are unaware. Brain-damaged patients own a knowledge of stimuli but they cannot perceive them with awareness.

Some neuropsychological syndromes involving dissociations between perception (mostly vision) and awareness of perception are quoted in most current philosophical works. For example, the following case histories became particularly popular: 1. blindsight patients (who have "blind" areas in their visual fields, but who however preserved visual abilities, despite no conscious awareness of perception); 2. prosopagnosics (who are unable to recognize even the faces of their own relatives, but however have "covert knowledge" of their facial expressions); 3. patients with neglect (who cannot report to the stimuli occurring on the side of space opposite to the lesion, their behavior suggests that they do not perceive stimuli, but they have non aware perception of neglected stimuli); 4. alexia patients (who can no longer read words at a glance, but who can implicitly read). All these patients have a "covert knowledge", an access to a knowledge of something without awareness so that they claim to be "guessing" (Farah 1994). Also 5. brain- 
split patients 6 . and epileptics ${ }^{2}$ came into vogue among philosophers of mind.

These syndromes are so interesting for philosophers because neuropsychological findings lead to a revision of the assumption that perception and consciousness of perception are always inseparably related. Philosophers are also interested in empirical issues, which help them understand the relations between the neural systems underlying perception and conscious awareness.

Therefore in the current work of philosophers of mind analysis of language and concepts are no longer so common as are case histories in order to know more about such issues as for example consciousness, its relationship with perception, and also about its physical basis.

This sketch shows that it has become evident that until now psychoanalytic case histories and, more importantly, their theoretical inferences have been left out of consideration by philosophers of mind. It shows that the common knowledge of other sciences about current psychoanalysis is too poor or too limited and that it is a necessary task, as this volume attempts to do, to bring current psychoanalytic research approaches and findings to the attention of other scientific disciplines, which pertain to the mental field (cf. also Giampieri-Deutsch 2003a, 2004a). At the same time this volume brings to attention those philosophers of mind such as David Rosenthal, Max Velmans and Pierre Jacob, who have already started to consider also psychoanalysis among the scientific disciplines of the mind.

\section{2. FREUD AND SCIENCE}

By reading Freud in the light of current analytic philosophy it becomes clear how little both his critics and his followers have understood Freud's own epistemologic approach. Nowadays when psychoanalysis increasingly carries out empirical research, it is important to remember how well founded and sound Freud's account of psychoanalysis as a science was (Giampieri-Deutsch 1992, 1999, 2003b). I will substantiate my statements by reference to Freud.

${ }^{2}$ Well-known is e. g. the epileptic patient HM, studied by Brenda Milner and Larry Squire (Milner, Squire \& Kandel 1998). HM had been operated and remained without his medial temporal lobe, parts of hippocampus and of amygdala in both hemispheres. He became amnestic, lost his conscious, declarative, explicit memory (memory about people, places, objects) and retained his unconscious, procedural, implicit memory (perceptual and motor skills). 


\section{2. 1. Freud: was he a monist or a dualist (a psychophysical} parallelist)?

I want to argue against the assumption that Freud by founding psychoanalysis abandoned the philosophical standpoint of monism in its form as physicalism and that he became a dualist.

I maintain that the position of Freud developed from a kind of physicalism, an ontological reductive physicalism, into another kind of physicalism, into a nonreductive physicalism and that he remained a monist and in so doing avoided the difficulties of dualism.

A comparison with the present debate in the current philosophy of mind allows us to understand Freud's theory of mind as being well established in this regard. I want to mention Jerry Fodor as a nonreductive physicalist who acknowledges both the mental as a legitimate object of scientific research and special sciences which are autonomous from physics (Fodor 1975).

\section{2. 2. Difficulties in holding a dualistic position}

Moritz Schlick, the founder of the Vienna Circle, had already pointed out the assumption of the closed causality of the world (Schlick 1925). Current analytic philosophy of mind has shown some difficulties of dualism concerning the following assertions. They are well-sketched, in German-speaking countries, in the so-called Bieri-Trilemma (Bieri 1993, p. 9):

Mental phenomena are not physical phenomena.

Mental phenomena cause physical phenomena.

The field of the physical phenomena is closed.

The first assumption characterizes a dualistic position.

The second one is the assumption of mental causation, which ascribes causality to mental states, events, phenomena.

The third assumption states that a physical phenomenon is only explained through a physical cause.

The three assumptions taken together contradict each other and the solution of most current analytic philosophy of mind is to understand mental phenomena as a particular kind of physical phenomena. This does not mean that the body causes the mind. Mental properties or qualities emerge or supervene at a particular high level of organisation of 
physical phenomena they are dependent upon it, but also not reducible to it.

This is the position of nonreductive physicalism.

\section{2. 3. Freud as a monist and as a nonreductive physicalist}

Freud's letter to Fließ from September 211897 has widely been considered as the beginning of psychoanalysis: mental events (e. g. sexual fantasies) cause mental illness (e. g. hysteria) (Freud 1985, p. 264266). Hysteria presents not only mental, but also physical symptoms: that is mental events cause physical events. Thus - according to a widely held assumption to be refuted in the following reflections Freud leaves physicalism and becomes a dualist.

But even in the year 1930 - 33 years after his discovery - Freud answered in a letter to Juliette Boutonier:

"I have no difficulty in acknowledging a physical world in addition to the mental world in the way that the latter [P. G.-D.: the mental world] is indeed a part of the former [P. G.-D.: the physical world]. The question of the relationship between physical and mental only applies to the latter (the mental). The physical world has a mental side in so far as it is also known by us only by means of mental perception. On the other hand our mental perceptions force us also to assume a physical reality behind mental life" (Freud 1955e [1930] translated by P. G.-D.). ${ }^{3}$

The psychical world was regarded by Freud as a "part", as a "side" of the physical world. This means that for Freud the mind is physically realized, embodied.

Contemporary philosophers, dualists and also monists do no longer speak of ultimate substances. If they are monists and nonreductive physicalists they refer to mental qualities in order to overcome the difficulties of the so-called Bieri-Trilemma.

${ }^{3}$ Freud wrote in his letter to Juliette Boutonier: “daß ich keine Schwierigkeit darin finde, eine physikalische Welt neben der psychischen anzuerkennen in der Art, daß die letztere [P. G.-D.: die psychische] ein Teilgebiet der ersteren [P. G.-D.: die physikalische] ist. Die Frage der Relation zwischen physikalisch und psychisch kommt nur für letztere[s] (das Psychische) in Betracht. Die physikalische Welt hat eine psychische Seit[e] insofern, als auch sie von uns nur durch psychische Wahrnehmung erkannt wird. Andererseits drängen uns unsere psychische[n] Wahrnehmungen auch die Notwendigkeit der Annahme einer physikalische[n] Realität hinter dem Seelenleben auf" (Freud 1955 e [1930], p. 672). 
Freud never considered the mind as another substance, but rather as a quality, as a property. The mental is in a very modern manner a quality, as Freud wrote in "Psychical Qualities", the $4^{\text {th }}$ chapter of An Outline of Psychoanalysis (Freud 1940a [1938], pp. 157-164).

Only now in the light of current philosophy of mind, of nonreductive physicalism, do Freud's assumptions show the novelty of his approach.

\section{2. 4. Freud was not a dualist in the form of parallelism}

In On Aphasia Freud wrote something which was to be misunderstood as an assumption of parallelism following Jackson.

"The relationship between the chain of physiological events in the nervous system and the mental processes is probably not one of cause and effect. The former do not cease when the latter set in; they tend to continue, but, from a certain moment, a mental phenomenon corresponds to each part of the chain, or to several parts. The psychic is, therefore, a process parallel to the physiological, 'a dependent concomitant" (Freud 1891b (1), p. 55).

In order to understand this quotation it is important to look closely at the description itself and not to be mislead by the terminology.

The sentence "The relationship between the chain of physiological events in the nervous system and the mental processes is probably not one of cause and effect" means only that there are no psychophysiological laws, as yet. Is it perhaps a question of an "anomalous Monism" as investigated by Donald Davidson? Davidson's proposal in "Mental events" (Davidson 1970) is rather charming, because he, a monist and a physicalist, finally admitted mental events and challenged the reductionism of the other analytic philosophers, but it is at the same time also rather hazardous. Indeed still many years later Davidson maintained: "The basic concepts of psychology are [...] not reducible to those of physics, and therefore do not lend themselves to inclusion in a systematic, precise and closed system of description and laws. This is why, particularly when we want to talk of the relations between events described in psychological terms and events described in physical terms, we make necessary use of causal concepts; these give us the sort of forgiving conceptual connections and explanations we want" (Davidson 1993, p. 312). According to Davidson the mental is anomalous and for this reason he argued against the possibility of strict psychological laws. 
However without laws there is no science, therefore according to Davidson psychology is no longer a science, but rather a philosophical discipline. ${ }^{4}$

When Freud noticed "from a certain moment, a mental phenomenon corresponds to each part of the chain, or to several parts" he told us that at a particular instant the mind supervenes to the physical or emerges from the physical.

The dependence-thesis is emphasized by the remark "a dependent concomitant". Interestingly, what appears as a quotation from Jackson cannot be found in any of Jackson's writings quoted by Freud, but is actually Freud's own words. ${ }^{5}$ Although Jackson was a parallelist Freud did not follow him in this regard even though Freud adopted the term "process parallel".

Scholars who maintain that Freud was a parallelist seem to ignore that the dualistic theory of parallelism says that there is no causal relation at all between the mental and the physical, the two domains are entirely unrelated. Therefore mental processes and physical processes run as two clocks synchronously, completely independent of each other and subject to God as the clock-maker, as the philosopher Leibniz in his well-known example stated.

Exactly the opposite is true, because the physical and the mental were regarded by Freud throughout his career from the beginning as a causally connected "continuum". In 1915, in "The unconscious", Freud could formulate this point in a very clear manner, when he referred to "the insoluble difficulties of psycho-physical parallelism" (Freud, 1915 $\mathrm{e}, 168$ ) showing that he was fully aware of the philosophical discussion about this topic. But already in his letter to Fließ in September 22, 1898 Freud wrote:

"I am $[\ldots]$ not at all inclined to leave the psychology hanging in the air without an organic basis. But apart from this conviction I do not know how to go on, neither theoretically nor therapeutically, and therefore must behave as if only the psychological were under consideration" (Freud 1985, p. 326).

${ }^{4}$ For a critique of Davidson's philosophy of science see Giampieri-Deutsch (2004b, pp. 84-87).

${ }^{5} \mathrm{Cf}$. footnote 2 of Paul Vogel, the editor of the original German edition Zur Auffassung der Aphasien. Frankfurt am Main: Fischer 1992 (Freud 1891b (2), p. 98). 
Throughout the "Project for a scientific psychology" monism is emphasized as a unity, an integrated whole of the physical and the mental (Freud $1950 \mathrm{c}$ [1895]).

In Three Essays on Sexuality drives are representatives of the somatic element which is the basis of the mind: "By an 'instinct' is provisionally to be understood the psychical representative of an endosomatic, continuously flowing source of stimulation [...] The concept of instinct is thus one of those lying on the frontier between the mental and the physical. The simplest and likeliest assumption as to the nature of instincts would seem to be that in itself an instinct is without quality, and, so far as mental life is concerned, is only to be regarded as a measure of the demand made upon the mind for work" (Freud $1905 \mathrm{~d}$, p. 168).

Freud did not abandon the view that psychoanalysis would find a link to neurobiology: "The theoretical structure of psycho-analysis that we have created is in truth a superstructure, which will one day have to be set upon its organic foundation" (Freud 1916-17 a [1915-17], p. 388).

As he later insisted in The Question of Lay Analysis: "In view of the intimate connection between the things that we distinguish as physical and mental, we may look forward to a day when paths of knowledge and, let us hope, of influence will be opened up, leading from organic biology and chemistry to the field of neurotic phenomena" (Freud 1926 e, p. 231).

\section{2. 5. Freud on epiphenomenalism}

In the section "The consciousness" in the first part of the "Project for a scientific psychology" Freud commented upon other theories of consciousness of his time: "According to an advanced mechanistic theory, consciousness is a mere appendage to physiologico-psychical processes and its omission would make no alteration in the psychical passage [of events]." Indeed Freud remarked upon the epiphenomenalism of Huxley. Freud argued against epiphenomenalism because this approach rejected the possibility of mental causation and instead explained his own theory: "Here consciousness is the subjective side of one part of the physical processes in the nervous system, namely of the $\Omega$ [omega] processes; and the omission of consciousness does not leave psychical events unalterated but involves the omission of the contribution from $\Omega$ [omega]" (Freud 1950c [1895], p. 311). 


\section{2. 6. Freud and causality}

Scientific thought is characterized by the assumptions of both dependence and determination, in a word causality. The world is not an accumulation of unrelated phenomena, events, objects, but it constitutes a system and this conception of the world, the scientific Weltanschauung shared by Freud but also by the Vienna Circle (GiampieriDeutsch 1997), the interrelatedness of things is the basis of our scheme of things. A mental or a physical thing is dependent on another thing or is determined by other things. This then brings about scientific knowledge i. e. explanation, prediction and control of events. Determination is not determinism. Determination is a concept which belongs to the theory of science, determinism is a concept which belongs to the ideology of science.

By taking this seriously Freud had to assume the existence of the unconscious: "the equation of what is mental with what is conscious had the unwelcome result of divorcing psychical processes from the general context of events in the universe and of setting them in complete contrast to all others" (Freud 1940 b [1938], p. 283).

In The Interpretation of Dreams Freud pointed out his contemporaries' distrust in and at the same time his own trust in causality: Freud was dealing here with the question of mental causation: "It is true that the dominance of the brain over the organism is asserted with apparent confidence. Nevertheless, anything that might indicate that mental life is in any way independent of demonstrable organic changes or that its manifestations are in any way spontaneous alarms the modern psychiatrist, as though a recognition of such things would inevitably bring back the day of the Philosophy of Nature, and the metaphysical view of the nature of mind. The suspicions of the psychiatrists have put the mind, as it were, under tutelage, and they now insist that none of its impulses shall be allowed to suggest that it has any means of its own. This behaviour of theirs only shows how little trust they really have in the validity of a causal connection between the somatic and the mental. Even when investigation shows that the primary exciting cause of a phenomenon is psychical, deeper research will one day trace the path further and discover an organic basis for the mental event. But if at the moment we cannot see beyond the mental, that is no reason for denying its existence" [Emphasis of P. G.-D.] (Freud 1900a, pp. 41-42). 


\section{3. PSYCHOANALYSIS AS A SCIENCE}

From the beginning to the later writings and even to the very last posthumously published manuscripts Freud looked at psychoanalysis constantly, continuously, and persistently as a natural science. Was it a "scientistic self-misunderstanding" as Habermas argued in his wellknown book Knowledge and Human Interest (Habermas 1968, p. 246)? In this regard Grünbaum defended Freud's epistemologic position against Habermas' interpretation (Grünbaum 1984, p. 8).

Freud explained in his posthumously published manuscript "Project for a scientific psychology" which he intended to become a "psychology for neurologists" as he wrote in the letter to Fließ of April 27 1895): "The intention is to furnish a psychology that shall be a natural science: that is, to represent psychical processes as quantitatively determinate states of specifiable material particles [...]" (Freud 1950c [1895], p. 295).

Not long after this Freud gave up trying to reduce clinical theory to neurobiology. He abandoned ontological reduction in favour of a nonreductive methodologic physicalism.

The ontological reduction of the ontological physicalism, the first old fashioned version of physicalism, which was the account of Helmholtz, Du Bois-Reymond and of Freud's teacher Brücke, stated that everything which can be studied scientifically is a physical thing. Freud rejected this approach as he pointed out for example in "Psychical (or mental) treatment": "After a somewhat unfruitful period during which it [P. G.-D.: medicine] was dependent on what was known as "Natural Philosophy", it came under the happy influence of the natural sciences and has achieved the greatest advances alike as a science and as an art [...] All of these advances and discoveries were related to the physical side of man, and it followed, as result of an incorrect though easily understandable trend of thought, that physicians came to restrict their interest to the physical side of things and were glad to leave the mental field to be dealt with by the philosophers whom they despised" (Freud 1890a, pp. 283-284).

But Freud also rejected the theoretical reduction of the theoretical physicalism or mechanism which is a second account of physicalism stating that the laws of every science are derived from or can be reduced by the theories of physics. An example in "Resistances to psychoanalysis" illustrates how clearly Freud differentiated between physical- 
ism and mechanism: "During the materialistic or, rather, mechanistic period, medicine made tremendous advances, but it also showed a shortsighted misunderstanding of the most important and most difficult among the problems of life" (Freud 1925e [1924], p. 216).

Physicalism does not have to be a form of theoretical reductionism and does not have to take physics as a model as mechanism does. This second version of physicalism does not deny the reality of mental phenomena, but devalues the theories of other sciences, so named "special sciences" by Ned Block and Jerry Fodor, such as psychology, sociology, economics, etc., the theories of which can not be derivable from the theory of physics (cf. Giampieri-Deutsch 2004b). The claim is that concepts of scientific theories have to be reduced by means of "operational definitions" to proceedings whose outcomes can be tested through observation.

Freud committed himself to a third version of physicalism, a very modern, for his time revolutionary and until now a little understood approach, the methodologic physicalism. Freud's nonreductive methodologic physicalism claimed rather that science discovers regularities in the relationship between phenomena, studies their causal relations and proposes generalizations, laws and explanations. All scientific knowledge is provisional and is subject to testing and control (Freud 1933a [1932], pp. 172-173). According to Freud every science has to meet this standard.

\section{3. 1. But why did Freud speak of 'natural science' and not just of 'science'?}

Freud's impressive knowledge of philosophy of science was derived from his teacher Franz Brentano, as I maintained in several of my studies on Freud's relationship with philosophy. Brentano is generally known for his theory of intentionality. As a Darwinist, as a methodologist, and as the grandfather of the Vienna Circle he is not so wellknown. For Brentano natural science was synonymous with empirical science, but this does not entail a reduction to physics. Brentano wrote in 1866 as the $4^{\text {th }}$ thesis for his venia docendi: "The true method of philosophy is none other than that of natural science." At the beginning of

\footnotetext{
${ }^{6}$ "Vera philosophiae methodus nulla alia nisi scientiae naturalis est" (Brentano 1924, p.136).
} 
his Psychology from an Empirical Standpoint he stated: "My place in psychology is at the empirical viewpoint. My only master is experience" (Brentano 1874, p. 1).

As Freud himself stressed in his An Autobiographical Study he always regarded it as an unfairness to psychoanalysis that it had not been considered in the same way as any other natural science: "I have always felt it as a gross injustice that people have refused to treat psychoanalysis like any other science" (Freud 1925d [1924], p. 58).

As Freud later explained in "Some elementary lessons in psychoanalysis" about "The nature of the psychical": "Psycho-analysis is a part of the mental science [Seelenkunde] of psychology. [...] Psychology, too, is a natural science. What else can it be?" (Freud 1940b [1938], p. 282).

In the $35^{\text {th }}$ lesson of New Introductory Lectures on Psycho-Analysis "The question of a Weltanschauung" in the year 1933 Freud leaves no doubt about his own epistemologic position on this subject: "the intellect and the mind are objects for scientific research in exactly the same way as any non-human things. Psycho-analysis has a special right to speak for the scientific Weltanschauung at this point, since it cannot be reproached with having neglected what is mental in the picture of the universe. Its contribution to science lies precisely in having extended research to the mental field. And, incidentally, without such a psychology science would be very incomplete. If, however, the investigation of the intellectual and emotional functions of men (and of animals) is included in science, then it will be seen that nothing is altered in the attitude of science as a whole, that no new sources of knowledge or methods of research have come into being" (Freud 1933a [1932], p. 159).

In the posthumously published An Outline of Psycho-Analysis Freud concluded: "Whereas the psychology of consciousness never went beyond the broken sequences which were obviously dependent on something else; the other view, which held that the psychical is unconscious in itself, enabled psychology to take its place as a natural science like any other. The processes with which it is concerned are in themselves just as unknowable as those dealt with by other sciences, by chemistry or physics, for example; but it is possible to establish the laws which they obey and to follow their mutual relations and interdependences unbroken over long stretches - in short, to arrive at what is described as an 'understanding' of the field of natural phenomena in question" (Freud 1940a [1938], p. 158). 


\section{3. 2. Concepts in psychoanalysis, as in every other science, are indeterminate and not invariable}

In An Outline of Psycho-Analysis, already referred to above, Freud pointed out that "the basic concepts and principles of the new science (instinct, nervous energy, etc.) remain for a considerable time no less indeterminate than those of the older sciences (force, mass, attraction)" (Freud 1940a [1938], p. 159).

Metapsychological basic concepts like those of the theory of mind are not invariable, unchangeable as a long tradition beginning with Robert Waelder (Waelder 1962) and Benjamin B. Rubinstein (Rubinstein 1967) has believed it to be. These concepts - as Freud stated very clearly in this regard from the point of view of current philosophy of science - "can lay claim to the same value as approximations that belongs to the corresponding intellectual scaffolding found in other natural sciences, and we look forward to their being modified, corrected and more precisely determined as further experience is accumulated and sifted" (Freud 1940a [1938], p.159).

By the way, Freud unmistakably expressed his own view on this topic even as late as 1925 in his autobiography: "Clear basic concepts and sharply drawn definitions are only possible in the mental sciences [Geisteswissenschaften] in so far as the latter seek to fit a region of facts into the frame of a logical system. In the natural sciences, of which psychology is one, such clear-cut general concepts are superfluous and indeed impossible. [...] The basic ideas or most general concepts in any of the disciplines of science are always left indeterminate at first and are only explained to begin with by reference to the realm of phenomena from which they were derived; it is only by means of a progressive analysis of the material of observation that they can be made clear and can find a significant and consistent meaning" (Freud 1925d [1924], pp. 57-58).

\section{2. "FIRST-PERSON PERSPECTIVE” AND “THIRD-PERSON PERSPECTIVE” IN PSYCHOANALYSIS}

I will apply both terms "first-person perspective" and "third-person perspective" to psychoanalysis as they are understood and used in current analytic philosophy of mind. I will not be considering some influential classical linguistic investigations of analytic philosophy. For in- 
stance Donald Davidson confined the problem of "first-person perspective" into a narrower frame as "self-attribution" and "self-ascription", by considering it, the "first-person perspective", "only as it applies to propositional attitudes like belief, desire, intention" (Davidson 1984, p. 3). Although such studies are - now as before - seminal, I would like to emphasize some new aspects of the concepts "first-person perspective" and "third-person perspective", which have arisen from the current debate in order to point out: first, the kind of knowledge and data provided by clinical research and empirical research in psychoanalysis; and second, that the particular knowledge of psychoanalysis in interdisciplinary dialogue with related fields can provide answers to some of the questions of other disciplines, for instance to the "other minds problem" of philosophy of mind.

Within the classical analytic philosophy the "first-person perspective" was originally the answer to the question about the access to the knowledge of one's own mind. Direct knowledge, privileged access, privacy, first-person authority, incorrigibility and self-evidence were some of the classical epistemological criteria, which analytic philosophers elaborated on.

The perspectivity of these points of view includes the epistemic asymmetry in the investigation of mind. The view from the "thirdperson-perspective" is a view "from outside", but the view from the "first-person perspective" is not only "from inside", but also "for oneself". Current analytic philosophy of mind uses the term first-person perspective connected to or even interchangeably with terms such as subjectivity, subjective experience, "what it is like to be" mental state, "raw feels", phenomenal consciousness, subjective awareness, phenomenal properties, qualia, qualitative character of experience and a variety of others so that the "first-person perspective" can at best be defined ostensively (Güzeldere 1997, pp. 42-43; Searle 1992, pp. 83ff.). In front of the linguistic analysis of classical analytic philosophy the current ostensive definition of the term "first-person perspective" in philosophy of mind may be criticized as circular, it seems that, as Ned Block notices, "really all one can do is point to the phenomenon" (Block 1995, p. 380). Some philosophers matintain that to refer the phenomenal aspect of the mind exclusively to sensory properties is a misunderstanding, as Robert van Gulick states: "Phenomenal experience is not merely a succession of qualitatively distinguished sensory ideas, but rather the organized cognitive experience of a world of objects and of ourselves as subjects within that world" (Van Gulick 1993, p. 137). 


\section{1. SOME OBJECTIONS FROM CONTINENTAL AND}

\section{ANALYTIC PHILOSOPHY AS WELL AS FROM THE COMMON SENSE OF THE}

\section{PSYCHOANALYSTS}

Psychoanalysis is the science, which integrates the "first-person perspective" in its own approach to the investigation of mental states (Giampieri-Deutsch 2003b, p. 64). However was it not exactly Freud who unveiled the deceptive inner perception of his patients and pushed forward to their unconscious thoughts and threatened the status of one's knowledge?

So at first glance my definition of psychoanalysis as the science which integrates the "first-person perspective" may sound quite challenging. There are at least two philosophical traditions which both seem to question this statement, Continental philosophy and analytic philosophy. Furthermore we should consider the everyday clinical experience of my colleagues and of myself, who have to question the first-person authority of the patients.

Concerning Continental philosophy Paul Ricœur defined Freud together with Nietzsche and Marx - as one of the "masters of suspicion" (Ricœur 1965), who taught us that the first-person authority misleads us and should be interpreted. Michael Foucault also argued in a similar vein in 1967 that after Freud - again connected with Nietzsche and Marx - "l'interprétation est enfin devenue une tâche infinie" (Foucault 1967, p. 187).

Among the analytic philosophers Joseph Agassi showed a similar understanding of Freud: "The doctrine of privileged access is that I am the authority on all my own experiences [...] The thesis was refuted by Freud (I know your dreams better than you) [...]" (Agassi 1975, p. 120) Everyday clinical experience shows us psychoanalysts the illusions of the authority of the "first person perspective", for instance in the transference. A tentative definition of the mark of psychoanalysis among the other psychotherapies is, that its major concern is about detecting and interpreting transference. Additionally transference is exactly the mental (and bodily) phenomenon in which the authority of the "first-person perspective" seems dramatically to fail.

These objections weaken, if the concept of the "first-person perspective" is understood more widely.

A report given in first-person terms generally describes an experience in terms of how it feels to the subject who experiences it (cf. Farrell 1950; Nagel 1974; Jackson 1982, 1986; Shoemaker 1993). In the 
current debate the "first-person perspective" is no longer seen as a sort of Cartesian transparency (a special inner perception). The discussion in analytic philosophy of mind addresses a very crucial topic. Although psychoanalysis questions the "first-person perspective", this perspective is absolutely necessary for it. Psychoanalysis has always known what current analytic philosophy of mind is now discovering: mental states of the first-person have not only a cognitive content, they also feel to the subject in a particular way?. Mental states of the first-person allow a particular epistemic access to some "what it is like to be" states not least through intersubjective reflective working through. Otherwise the psychoanalytic clinical method, which is based on free associations and insight of the analysand, would not be possible.

In current analytic philosophy of mind the "first-person perspective" is often misunderstood as a solipsistic and unknowable mental state, but psychoanalytic experience provides some advances in the philosophical understanding of this matter.

Are the "first-person perspective" and the "third-person perspective" mutually exclusive? Max Velmans' contribution in this volume addresses this point (see below). In my opinion too, psychoanalysis seems to be the best living proof of an integration of both perspectives in a science.

\section{2. "FIRST-PERSON PERSPECTIVE" AND "THIRD-PERSON PERSPECTIVE" IN CLINICAL PSYCHOANALYTIC RESEARCH}

Psychoanalytic clinical method provides a systematic exploration of subjective experience and is a source of clinical data about the mind. In the clinical situation the analyst knows from the "first-person perspective" in evenly hovering attention and in the phenomena of countertransference and projective identification. However the analyst knows also from the "third-person perspective" on two different levels: on the first level in clinical work and research by writing case histories, by participating in supervision, in intervision, or in case history seminars. There is also a second level of the "third-person perspective" the psychoanalytic empirical research, which claims more compelling "objectivity" and which I will consider later.

\footnotetext{
${ }^{7}$ Wittgenstein wrote in $\S 302$ of his Philosophical Investigations "If one has to imagine someone else's pain on the model of one's own, this is none too easy a thing to do: for I have to imagine pain which I do not feel on the model of the pain which I do feel" (Wittgenstein 1953, p. 101).
} 
I would like to introduce the concept of projective identification. It is the way in which a subject, the patient, makes use of another subject, the analyst, to experience aspects of himself. In this case the analyst is pressured to experience and feel - including bodily - in a way that is congruent with the experience of the patient (cf. Ogden 1982, pp. 2223). Sándor Ferenczi discovered it as early as 1911 as ' ' $L$ ' autre danger' that the psychoanalyst is subject to [...] Besides monitoring the countertransference, one must therefore also pay heed to this 'being induced' by the patients. (Perhaps it is only a question here of a form of countertransference)." as Ferenczi (letter 198 Fer) wrote to Freud on February 1911 (Freud \& Ferenczi 1993, p. 253; cf. Giampieri-Deutsch 1996). Today one cannot say that the concept projective identification "belongs" to any particular school, but Melanie Klein officially introduced it in "Notes on some schizoid mechanism" (Klein 1946). A very important point made by Melanie Klein is that a subject projects not "onto" but rather "into" another person". The analyst is not only a mirror in which the internal objects of the patients are reflected in the transference. The patient projects, "puts" his or her feelings and fantasies not only onto the analyst but also into him or her.

According to experienced clinicians such as Bott-Spillius: "patients can behave in ways that get analysts to feel the feeling that the patient, for one reason or another, cannot contain within himself or cannot express in any other way except by getting the analyst to have the experience too" (Bott-Spillius 1992, p. 61). "The analyst's aim is to allow himself or herself to experience and respond internally to such pressures and of its contents so that he can interpret it, but without being pushed into gross acting out. Some degree of acting out by the analyst, however, is often inevitable in the early stage of what the patient is feeling $[\ldots]$ " (Bott-Spillius 1992, p. 63). The clinical experience also teaches that "the analyst is always affected to some degree by his patient's projections" (Bott-Spillius 1992, p. 64).

A phenomenon experienced from the "first-person perspective" in everyday clinical life becomes in psychoanalytic clinical research a phenomenon observed from the "third person perspective" and therefore a result. According to Ogden: "Unlike many of the 'beliefs' of the different schools of psychoanalytic thought, projective identification is not

8 "Together with these harmful excrements, expelled in hatred, split-off parts of the ego are also projected onto the mother, or, as I would rather call it, into the mother" (Klein 1946, p. 8). 
a construct that one accepts or rejects on the basis of an attraction to a metaphor [...] Projective identification is a clinical-level conceptualization with three phenomenological references, all of which lie entirely within the realm of observable psychological and interpersonal experience: (1) the projector's unconscious fantasies (observable through their derivatives, such as associations, dreams, parapraxes, and so forth); (2) forms of interpersonal pressure that are often subtle but verifiable; and (3) countertransference experience (a real, yet under-utilized source of analysable data)" (Ogden 1982, pp. 45-46).

Psychoanalytic clinical findings as well as their theoretical inferences have not yet been considered enough by philosophers of mind and scientists. The common knowledge of related sciences about current psychoanalysis is still quite limited and current psychoanalytic results should be shared with related sciences and disciplines. But "clinical data" is held to be "weak data". For this reason psychoanalytic empirical research tries to provide "empirical data", which can be considered "hard data" form the points of view of both experimental sciences and philosophy of mind. ${ }^{9}$

Until now current discussion in analytic philosophy of mind related "first-person perspective" to consciousness. Nonetheless from the comparison between philosophy of mind and clinical psychoanalytic experiences some questions arise: For example, should the "first-person perspective" be considered as a conscious state from a psychoanalytic point of view? Or can it also be conscious, preconscious or unconscious? David Rosenthal, a philosopher of mind who is also committed to psychoanalysis, also addresses this question in his contribution to this volume and argues that phenomenal states can be conscious, but they don't necessarily have to be conscious (see below). Lastly, should the "firstperson perspective" be considered merely a mental state or rather a psychophysical state?

\section{3. THE PARTICULAR KNOWLEDGE OF PSYCHOANALYSIS, WHICH CAN}

\section{PROVIDE ANSWERS TO SOME QUESTIONS IN OTHER DISCIPLINES}

Psychoanalysis can, in interdisciplinary dialogue and mutual exchange, learn a lot from related fields as cognitive psychology, cognitive neuroscience, neurobiology, philosophy of mind, linguistics and meth-

\footnotetext{
${ }^{9}$ Concerning the experimental testing of Freud's theory and clinical method see Fisher \& Greenberg $(1985,1996,2002)$.
} 
odology. This present volume shows several interdisciplinary contributions to the growth of psychoanalysis as a theory of mind, as a clinical theory, and as a discipline, which is active in both clinical and empirical research.

I would like to point out, that there are a lot of obvious clinical phenomena and observations, which every psychoanalyst is aware of and that could contribute to solving what is supposed to be a "mystery" in other related disciplines. The rich common knowledge of the psychoanalyst practitioner is often undervalued by himself or by herself.

\section{4. THE "OTHER MINDS PROBLEM": HOW CAN WE KNOW THE MINDS OF OTHERS?}

The old version of the problem emphasized the cognitive aspect. In $\S 243$ of his Philosophical Investigations Wittgenstein elaborated on the "first-person perspective" and its epistemological criterion of privacy: "But could we also imagine a language in which a person could write down or give vocal expression to his inner experiences - his feelings, moods, and the rest - for his private use? - Well, can't we do so in our ordinary language? - But that is not what I mean. The individual words of this language are to refer to what can only be known to the person speaking; to his immediate private sensations. So another person cannot understand the language" (Wittgenstein 1953, p. 89).

The connection between the authority of the "first-person perspective" and the traditional problem of "other minds" was clearly formulated by Wittgenstein: "I cannot know what is going on in him" (Wittgenstein 1953, p 223). And: "What is internal is hidden from us" (Wittgenstein 1953, p. 223).

Wittgenstein was also concerned with the possibility of knowing other minds by "guessing" or by "reading": "“What anyone says to himself within himself is hidden from me' might of course also mean that I can for the most part not guess it, nor can I read it off from, for example, the movements of his throat (which would be a possibility)" (Wittgenstein 1953, p 221). In the next pages Wittgenstein insisted: "There is a game of 'guessing thoughts"' (Wittgenstein 1953, p 223).

A classical tentative solution was to argue, that behavior allows us to know other minds, because behavior was held to be observable. In his Philosophical Investigations Wittgenstein wrote for instance: "A doctor asks: 'How is he feeling?' the nurse says: 'He is groaning.' A report on 
his behaviour." (Wittgenstein 1953, p 179) As Davidson remarks: "Since Wittgenstein it has become routine to try to relieve worries about 'our knowledge of other minds' by remarking that it is an essential aspect of our use of certain mental predicates that we apply them to others on the basis of behavioral evidence but to ourselves without benefit of such aid" (Davidson 1987, p. 16).

The new version of the problem emphasized the phenomenal aspect (sensations, emotions, bodily feelings). In Thomas Nagel's text "What is it like to be a bat?" from 1974 the perspectivity of the "first-person" is directly understood as a subjective feeling of the mind, as a first-person feeling, as a "what it's like to be" feeling: "the fact that an organism has conscious experience at all means, basically, that there is something it is like to be that organism" (Nagel 1974, p. 519). It is the phenomenal facet which is focused on here. The subjective character of the experience can be grasped from only one point of view, from the first-person perspective: "we believe that these experiences also have in each case a specific subjective character, which it is beyond our ability to conceive" (Nagel 1974, p. 521).

Among the current philosophers of mind the naturalist Owen Flanagan, who is quite sympathetic to psychoanalysis, solves the "other minds problem" with an intuitive argument: "The metaphor of us as mental detectors is a powerful one. Just as a metal detector detects metal objects beneath the sand or between blades of grass, so too mental detectors detect invisible mental states. Good mental detectors understand a great deal about the form of life in which they live and about behavioral regularities" (Flanagan 1992, pp. 102-103). "Persons understand each other, but not by penetrating each other's being, not by having each other's experiences. Understanding another involves conceiving of the other's experiences" (Flanagan 1992, p. 106). Flanagan concludes: "There are other minds, and we have knowledge of them" (Flanagan 1992, p. 107). According to Flanagan there is no reason why a naturalist cannot both acknowledge the existence of subjectivity and the subjective "first-person perspective" by getting a description of them as a part of the general project of understanding the mind. The philosopher of mind Pierre Jacob discusses findings of cognitive science on mindreading in his contribution to this volume (see below).

I would also like to present some possible solutions to the "otherminds problem" offered by psychoanalytic clinical research and by psychoanalytic empirical research. 
2. 4. 1. A tentative solution by psychoanalytic clinical research: projective identification

One can know other minds by everyday projective identification. This mechanism, obtained from clinical psychoanalytic research, is not restricted to psychopathology. Projective identification can be generalized to everyday life situations. León Grinberg described in "Countertransference and projective counteridentification", how projective identification - a phenomenon discovered in a clinical situation - occurs as "normal" phenomenon in everyday life: "Under normal conditions projective identification determines the empathic relationship with the object, not only because it allows one to put oneself in the place of the other and therefore understand his feelings better, but also for what it brings out in that person. The subject produces some emotional reaction in the object. [...] This usually happens, within certain limits, in all human relationships and forms the basis of the communication" (Grinberg 1979, p. 170).

\section{4. 2. A tentative solution by psychoanalytic empirical research: mentalization}

A further solution to the "other minds problem" is provided by psychoanalytic empirical research. Peter Fonagy's empirically rooted theory of mentalization refers to the studies of Baron-Cohen and colleagues (Baron-Cohen 1995; Baron-Cohen, Tager-Flusberg \& Cohen 1993) and offers an excellent answer to mindreading: "Reflective function, or mentalization, enables children to 'read' other people's minds. By doing this, children make people's behavior meaningful and predictable" (Fonagy, Gergely, Jurist \& Target 2002, p. 24). Mentalizing, a central aspect of social cognition, entails implicitly or explicitly perceiving or interpreting the behavior of others and oneself as intentional, i.e., mediated by mental states and processes. This developmental acquisition permits not only response to another person's behavior but to his "beliefs, feelings, attitudes, desires, hopes, knowledge, imagination, pretense, deceit, intentions, plans, and so on" (Fonagy, Gergely, Jurist \& Target 2002, p. 24). According to Fonagy, making sense of minds is central to the diagnostic work of psychoanalysis and the experience of another human being. Having one's mind in mind is central to the impact of therapies, ranging from cognitive therapy to psychoanalysis. Fonagy relates mentalization to clinical concepts such as "introspection", "observing ego", "insight", and "empathy". 
I would like to summarize some central thoughts of Fonagy about mentalization, which are relevant to the topic under discussion. Reflective functioning refers to the mental processes underlying the capacity to mentalize. It expresses the mental capacity related to the representation of the self and involves a self-reflective and interpersonal component. Reflective functioning or mentalizing is the "capacity to perceive and understand oneself and others in terms of mental states (feelings, beliefs, intentions and desires) [...] to reason about one's own and others' behavior in terms of mental states, i.e. reflection" (Fonagy, Target, Steele $\&$ Steele, 1998, p. 7). According to Fonagy, reflective functioning works unconsciously like an automatic procedural knowledge of the mind. Therefore Fonagy distinguishes reflective functioning from introspection or self-reflection, which are restricted to consciousness and are rather declarative self-knowledge or self-report, whereas reflective functioning refers to the ability to give sense to a behavior and to adjust it. The reflective function can be measured by the Reflective Functioning (RF) Scale, designed by Fonagy and colleagues (Fonagy, Target, Steele \& Steele 1998) for and currently applied to the protocols of the Berkeley Adult Attachment Interview (AAI) (George, Kaplan \& Main 1996)..$^{10}$ The Reflective Functioning (RF) Scale is mainly implemented in different designs of psychoanalytic outcome studies to investigate the effects of psychoanalytic treatment on the improvement of the capacity to understand one's own and others' mental states. But Fonagy and colleagues provide more than an impressive theory, by substantiating it in two ways: First, if "reading" other minds is no longer a mystery but a common capacity acquired in normal development, the development of this ability can be observed and investigated by both psychoanalytic developmental psychology and cognitive psychology; second, this capacity can not only be observed, but also be assessed by the Reflecting Functioning Scale. What makes the phenomenon of knowing other minds understandable is the attention in psychoanalytic clinical and empirical research to both cognitive and emotional aspects.

A paraphrase of a famous sentence of Wittgenstein (Wittgenstein 1953 , p. 222) provides a commentary: "A whole cloud of philosophy condensed into a drop of psychoanalysis."

${ }^{10}$ The Adult Attachment Interview (AAI) is a semistructured interview asking for the experiences of separation, illness, rejection and loss experienced by the interviewees in relation to the childhood caregivers, in order to assess the quality and the degree of their attachment to the significant others. 


\section{PSYCHOANALYSIS, PHILOSOPHY OF MIND AND EXPERIMENTAL SCIENCES: RESEARCH IN CONSCIOUS AND UNCONSCIOUS PROCESSES}

In "Toward a theory on consciousness based on recent developments in subliminal research" Howard Shevrin holds that one of the most important questions in contemporary psychology and neuroscience concerns the relationship between conscious and unconscious processes. According to Shevrin consciousness cannot be fully understood without a concomitant understanding of unconscious processes, and unconscious processes cannot be fully explained without an understanding of conscious processes. Shevrin maintains that this conjoint understanding can only be achieved by placing individuality at the heart of the solution. Consciousness theorists claim that subjectivity is the hallmark of consciousness. Shevrin points out that subjectivity is always individual. Shevrin argues that there cannot be a completely free standing theory of consciousness without taking the unconscious into account, or a theory of the interaction between conscious and unconscious processes without taking individual differences into account. According to Shevrin any quantitative or qualitative differences between conscious and unconscious processes can best be seen through the lenses of individual differences. Therefore research methods should study conscious and unconscious processes jointly as a function of these individual differences. Shevrin describes a number of studies that illustrate this position in order to support empirically the following four propositions by experimental findings: 1. consciousness cannot be fully understood without knowledge of unconscious processes; 2. unconscious processes are complex, representational, highly interactive with conscious processes and not dispositional or latent; 3 . the interaction between conscious and unconscious processes can best be understood when person and context are taken into account; 4 . there are quantitative and qualitative differences between conscious and unconscious processes. These propositions taken together make possible a different approach to conceptualizing the nature of consciousness and its relationship to unconscious processes from that currently prevailing in much research and theorizing in he field.

In "Drive theory and primary process: a philosophical account", the psychoanalyst and psychoanalytic researcher Linda Brakel describes and defines drives. According to Freud, drives are a boundary concept, a mental representative of a state of physiological need. Each drive has a 
source, an aim, and an object through which satisfaction can be obtained. Brakel carries out a philosophical analysis of drives. Drives are shown by Brakel not to be adequately explained in the analyses of standard propositional-attitude psychology. This is due to the fact that drives not have singular determinate objects. The non-singularity and high displace-ability of drive aims is taken up in contrast to the indeterminacy threatening representations of drive objects. Compared to aims, drive objects have no original singular object; instead the object of drives seem to be a primary process organized set of objects. Since standard means will not work for individuating representations of this nature, Brakel raises the question concerning what can save these nonsingular, primary process set type drive objects from being unconstrained and indeterminate. According to Brakel, a proper function naturalistic account of drive objects will make this possible, and thus a case is made for such primary process sets of objects having a proper function. For the proper function argument to be effective, it must be shown that such objects have a proper function under conditions which will enhance selective fitness, and this too is highlighted by Brakel. Finally, the objects of drives and their representations are contrasted, first with another sort of representation that can be individuated in a properfunction account, and then with representations understood philosophically as "vague" concepts.

The philosopher of mind and cognitive psychologist Max Velmans' contribution "Complementary first- and third-person approaches to the investigation of mind" presents his own view that, although first-person and third-person accounts of mind are not reducible to one another, they are not exclusive, but rather complementary. Psychosomatic medicine assumes that the conscious mind can affect body states, and this is supported by evidence that the use of imagery, hypnosis, biofeedback and other 'mental interventions' can be therapeutic in a variety of medical conditions. However, there is no accepted theory of mind/body interaction and this has had a detrimental effect on the acceptance of mental causation in science, philosophy and in many areas of clinical practice. Velmans maintains that the nature of mind can be partly revealed by mind/body interactions and particularly by the causal interactions of consciousness and brain. However, causal interactions between mind and body are not easy to understand. According to dualistinteractionists, brains and conscious experiences are entirely different kinds of substance that causally interact, but how they do so is not clear. According to physicalist reductionists conscious experiences are merely 
brain states, which explains their interaction with other brain states. However Velmans holds that reductionists habitually confound causation, correlation and ontological identity. Finding the neural causes and correlates of conscious experiences would not reduce those experiences to states of the brain. Biomedical accounts typically translate the effects of mind into the effects of brain functioning, for example, explaining $\mathrm{mind} /$ body interactions in terms of the interconnections and reciprocal control of cortical, neuroendocrine, autonomic and immune systems. While such accounts are instructive, they are implicitly reductionist, and beg the question of how conscious experiences could have bodily effects. If conscious states cannot be reduced to brain states, on the other hand the function of consciousness also poses problems, and according to Velmans non-reductionist accounts have to cope with three problems: First, the physical world appears causally closed, which would seem to leave no room for conscious intervention. Second, one is not conscious of one's own brain/body processing, so how could there be conscious control of such processing? Third, conscious experiences appear to come too late to causally affect the mental processes to which they most obviously relate. There are in any case different senses in which a mental process can be said to "be conscious". It might be conscious (a) in the way that we can become conscious of it, (b) or that it results in a conscious experience, and (c) in the sense that consciousness causally affects that process. Some processes are conscious in the sense of (a) or (b). However, it is uncertain whether any process is conscious in the sense of (c). Velmans points out that Freud arrived at a similar analysis of how the operations of unconscious mind relate to the contents of consciousness and had similar doubts about the causal efficacy of consciousness. However, this produces a paradox: viewed from a thirdperson perspective, consciousness seems unnecessary to the operations of mind, but viewed from a first-person perspective, it seems to be central to mental life. Velmans suggests a way to think about consciousness, unconscious mind and brain that allows this paradox to be resolved.

According to the philosopher of mind David Rosenthal in "Consciousness, interpretation, and higher-order-thought", a mental state is conscious only when the individual who is in this state is in some way conscious of being in that state. Rosenthal poses a central question for a theory of consciousness, which consists of what way of being conscious of a mental state constitutes its being actually conscious. Rosenthal argues that we are conscious of those states by having thoughts to the 
effect that we are in them. These higher-order thoughts are themselves seldom conscious, and they must occur independently of conscious inference. This model applies not just to cognitive and desiderative states, but equally to qualitative states, such as bodily and perceptual sensations and affective states. The model is supported by our being conscious of a given mental state in respect to different mental properties, and by confabulatory mental states, which we subjectively seem to be in, despite evidence that we are not. Rosenthal's model also helps to explain various connections between consciousness and speech. Finally, because one's having a suitable higher-order thought amounts to interpreting oneself as being in that state, a mental state's being conscious is a matter of one's noninferential self-interpretation.

The philosopher of mind and cognitive scientist Pierre Jacob presents in his contribution "First-person and third-person mindreading" some further current answers to the "other-minds problem" provided by philosophy of mind and cognitive science and offers a framework to better understand what Fonagy means by reflective functioning or mentalizing. According to Jacob, who like Fonagy refers to the developmental cognitive research of Baron-Cohen (Baron-Cohen 1995), mindreading is the cognitive ability to recognize the presence, and retrieve the contents, of human minds. First-person mindreading is knowledge of one's own mind. Third-person mindreading is knowledge of other minds. Jacob questions a recent influential proposal, which maintains that all forms of mindreading are accomplished by means of a simple cognitive heuristic: mental simulation. Jacob first argues that full-blown third-person mindreading lies outside the scope of mental simulation. Lastly, he maintains that mental simulation cannot even begin to provide an account of first-person mindreading.

\section{CURRENT INTERDISCIPLINARY RESEARCH: “FIRST-PERSON PERSPECTIVE” AND “THIRD-PERSON PERSPECTIVE” IN NEUROSCIENCE AND PSYCHOANALYSIS}

Psychoanalysis is the science which integrates the "first-person perspective" in its own approach to the investigation of mental states and at the same time attempts to understand subjective experience from the perspective of science. The "third-person perspective" is what is operant in the everyday scientific practice of experimental sciences and provides 
valuable advances in the understanding of the mind. The psychoanalyst wants to know how the way things seen from the "first-person perspective" match with data from the "third-person perspective" i. e. from other sources such as developmental psychology and cognitive neuroscience. In psychoanalytic empirical research the psychoanalyst as psychoanalytic researcher is able to integrate the special knowledge of psychoanalysis into research designs.

According to Karl Pribram the recent resurgence of interest in biology has reached also psychoanalysis. Now, therefore more than ever, Freud's "Project for a scientific psychology" (Freud 1950a [1895]) has relevance for those psychoanalysts and other mind-scientists working within the general framework provided by the psychoanalytic metapsychology. In his contribution "Freud's Project for a Scientific Psychology in the $21^{\text {st }}$ Century" Pribram summarizes some of Freud's propositions regarding brain function in the light of what we have learned during the past century. Pribram's interest in Freud's "Project" was aroused by two propositions: first, a memory based theory of motivation and second, an Ohm's law of neural processing. Two further areas of interest were developed by Pribram as he and Merton Gill began their studies prior to the publication of their book Freud's Project Reassessed (Pribram \& Gill 1976): the brain mechanisms involved in primary and secondary processes as well as the brain mechanisms in unconscious and especially conscious processes.

In her contribution Regina Pally "Emotion and the role of emotion in mental life" explains that emotions are not just subjective feelings. Emotions are as much about the body as are digestion and respiration. What neuroscience indicates is that these bodily aspects of emotion are very relevant to the clinical issues we address in psychoanalysis. They help to explain many of the symptoms of psychological disorders, and why they are so deeply entrenched. They also help to explain how empathy, transference, countertransference and psychological defenses occur, and even address the patient's often asked question "why do I have to feel my feelings?" Although emotion is now center stage in neuroscience and in psychoanalysis, there is one caveat. Some emotions are so deeply engrained we cannot change them, even with the best analysis. These patients will continue to have the old painful feelings and will have the impulse or tendency to act on those feelings. The experienced analyst Pally tell patients we have no control over how we feel, only over how we act. This need not be a negative outcome however, because patients in analysis, who are able to bring their emotions 
into conscious awareness, can learn to inhibit the maladaptive behavior, which results from that emotion.

Fred Levin provides a sample of neuropsychoanalysis. Levin is a pioneer in this field (Levin 1991, 2004), who combines psychoanalytic data with neuroscientific data, the "first-person perspective" and the "third-person perspective". Levin's "Synapses, cytokines and long-term memory. An interdisciplinary look at how psychoanalysis activates learning via its effects on emotional attention" is a paper about the novel neural learning networks and about what happens in mind/brain in relation to psychoanalysis that facilitates learning. When Levin began investigating how learning works, he discovered in 1980 a close link between metaphors coded into analytic interpretations and "aha" reactions in the patient. Levin speculated that such moments of insight were secondary to the simultaneous activation of the primary sensory association cortical zones for hearing, touch, and vision (i.e. the formation of novel neural networks). Later Levin learned from research by Neils A. Lassen suggesting that when an analytic patient feels relaxed and safe he or she becomes more spontaneous as seen in the appearance of free association, transference, and enactments of various kinds. What is important is that in association with such spontaneity, working memory is activated for what is remembered, and this is what makes the patient's learning much easier than usual. After a further review, Levin has recognized that it is possible to apply what is known about synapses, cytokines, and long-term memory, to appreciate that the neural network formation Levin and others speculated about in earlier research would likely be the result of cytokine effects on synaptic plasticity secondary to emotional attention. Insights are first associated with novel neural networks, longterm potentiation (LTP) or long-term depression (LTD), and eventually with new long-term memory (LTM). Learning in analysis thus involves three related activity levels: first, analytic spontaneity (free association and transference being the primary elements), along with, second, emotional attention, which reflects both superficial and deep affective motivational systems of the brain, and third, changes in the chemical matrix which the mind begins to work upon during any analysis. Regarding this third level of activity, which is the primary focus of Levin's paper, the analyst/patient couple facilitates the patient's creation of a state in which new synapses form on demand, simultaneously creating a spatially dispersed collection of neurons, leading to the formation of a novel neural network with the properties. Levin (1991) long ago elaborated on this, in which memory is highly activated and available to the patient (espe- 
cially working memory for the specific details recalled), and intersensory bridging invites comparisons (based on similarity and difference analysis) and novel insights. Consequently, neuropsychoanalysts can begin to correlate what the analyst does that facilitates a psychological cascade of affective attention, spontaneity, free association, transference, recollection and insight, and a parallel chemical cascade involving the patient's changing synaptic plasticity within systems under the control largely of cytokines. Regarding the psychological and the chemical cascade, at present it is not plausible that one cascade is primary and the other secondary; rather it seems more likely that these two cascades represent the recurrent interactive effects of mind on brain and brain on mind. When we are strongly moved emotionally, we produce changes in synaptic plasticity that further enable us to be so moved.

\section{EMPIRICAL RESEARCH TRENDS IN PSYCHOANALYSIS}

In addition to the tradition of "psychotherapy research", that originated mainly as outcome-oriented research, "psychoanalytic" research on outcome and process not only learned a lot from psychotherapy research, but it developed several of its own instruments as well as its own strategies (for instance: whereas psychotherapy is usually a short-term treatment, psychoanalytic treatment is a high-frequency and long-term treatment) (Shapiro \& Emde 1995). The psychoanalytic assessment instruments try to convert authentic psychoanalytic knowledge into reliable measurement techniques. For instance the Object Relations Inventory was created by Sidney Blatt and colleagues (Blatt, Wein, Chevron \& Quinlan 1979; Blatt, Chevron, Quinlan, Schaffer \& Wein 1988; Blatt, Levy \& Shaver 1998) to assess the structure and the contents of the self and the object representations of clinical subjects, mostly in order to measure the level of psychopathology, but also of non-clinical subjects. In developing the Object Relations Inventory and coding systems, Blatt and colleagues attempted to investigate how the contents and the structure of mental representations are involved in normal development, pathology and therapeutic change. The Object Relations Inventory is administered as an interview measure (although it can also be used as a self-report instrument). Blatt and colleagues developed two scales: First, "Qualitative and Structural Dimensions of Parental Descriptions" and second, "Differentiation-Relatedness Scale of Self and Object Representations" (Diamond, Blatt, Stayner \& Kaslow 1991). 
The latter scale can integrate clinical observations about early processes of separation-individuation, the formation of the sense of self and the development of interpersonal relatedness. While the Reflective Functioning Scale, which I already mentioned above, emphasizes some cognitive aspects of the representations of self and other, the Differentiation-Relatedness Scale points out more the affective and relational aspects of these representations.

Developmental research in psychoanalysis applies observation techniques to children and to adolescents such as Stuart Hauser's ground breaking empirical research on adolescents "Overcoming adversity in adolescence: narratives of resilience". According to Hauser resilience refers to unforeseen adaptation in the face of serious adversity. Through his narrative analyses of resilient young adults, Hauser has become aware of experiences of self and of relationships that had not been found through previous empirical procedures. For instance, more traditional analyses were theory-driven and constrained by rigorous coding conventions and technical language as the researchers pursued indices of defenses, adaptive strengths, self-images, expressed effects, and enabling interactions. In working with previous methods, Hauser often had the impression that he was not capturing significant aspects of the subject's experience; especially their vividly described poignant past and current relationships. Based on these explorations, Hauser concludes that there are good reasons to add narrative analyses to his ongoing life span studies. From Hauser's examination of more than 60 adolescent and adult interviews from the resilient patients - spanning over 20 years - he has a better grasp of resilient participants' constructions of themselves and their relationships during a time of major disruption; and he has seen ways these constructions change over time. In terms of the constructions of the self, Hauser found five content themes and one structural feature. First, self-reflection, this is illustrated by individuals' increasing awareness of their feelings and thoughts, within each adolescent year and in subsequently reflecting on their experience and performance as adults and new parents. Second, in the case of agency as adolescents, the resilient patients played an active part in deciding where they would go after leaving hospital and how they would take care of themselves when facing adversity again. As adults, they make conscious choices about parenting and how to apply their ideas in practice. Relating to this theme, the resilient adults' detailed visions of their future, and their conscious plans enable them to actualize these optimistic aspirations. Third, indicative of self-complexity, Hauser found evidence of complex continui- 
ties over time, the resilient subjects' recognizing parenting themes from their past; they accept their discovery of multiple perspectives about themselves, and about their friends. Fourth, regarding persistence and ambition, resilient patients describe a refusal to settle for a specific solution offered by a hospital, a therapist, or their family; several find new schools or return to complete training many years after forced breaks. Fifth, concerning self-esteem, ever apparent are the resilient participants' vacillating appraisals of themselves. By no means were these evaluations simply increasingly positive over the years. More significantly was their awareness of these self-evaluations, and the overall balance weighted in favor of more positive self-regard each year. Concerning the structural feature these were coherent narratives. Focusing on constructions of relationships, Hauser identifies three themes: the resilient adolescents strongly reflect on others' motives, feelings, and thoughts. Second, the resilient individuals attribute great importance to friendships. Finally, the resilient individuals are aware of many intersections between themselves, their relationships, and their actions; speaking, for instance, about how increasingly good feelings about themselves are leading to more positive ways in which they are searching for new friends.

As part of a wider attempt to understand and investigate at an empirical level, what we experience at a clinical level, i. e. a deep, stable change in our patients, the psychoanalyst and psychoanalytic researcher Rolf Sandell, director of the Stockholm Outcome of Psychoanalysis and Psychotherapy Project (STOPP-Project), has considered the definition and assessment of "structural change" a posteriori and not directly. In his study Sandell examines and compares the effects of psychoanalysis and long-term-therapy. From the point of view of the clinicians it remains the need to put together such impressive empirical findings with their own clinical experience. In his contribution for this volume "Structural change and its assessment. Experiences from the Stockholm Outcome of Psychoanalysis and Psychotherapy Project" Sandell analyzes the favoured psychoanalytic clinical concept of structural change with some questions in mind. This includes: What are the essential aspects of the kind of change that may be called structural (in contradistinction from non-structural kinds of change)? Is the structural kind of change specific to psychoanalysis or may it come about in other ways? Are all changes during psychoanalysis, structural? How may structural change be properly assessed? In his Introductory Lectures on Psycho-Analysis Freud asked himself if psychoanalysis was to be defined as a "causal" 
therapy opposed to symptomatic therapies, which do not search for the causes but treat only the effects of the illness (Freud 1916-17 a [191517], pp. 435-436). In the original STOPP-Project Sandell did not integrate a particular investigation or measure for assessing structural change a priori. This investigation occurred only later on. This is because at the beginning Sandell assumed a neutral point of view. He did not take for granted that structural change occurs in psychoanalysis and even questioned that it has to be considered a peculiarity of psychoanalysis. Nevertheless according to Sandell one of the important results of the STOPP-Project is that psychoanalysis may be expected to produce stable change, i. e., structural change. Sandell differentiates between three kinds of "structural change": first, structuring or stabilizing a system that is less stable, for example an increased capacity of the ego to bind energy; second, restructuring, for instance a non-adaptive solution to a conflict is replaced by an adaptive solution, the super-ego becomes more benign; third destructuring or destabilizing, i. e. in the case of a patient suffering from an obsessive-compulsive neurosis. According to Sandell a "structural change" is a permanent, enduring change, which is unobservable and has to be inferred on the basis of indicators of underlying structures, when symptoms disappear, and no new symptom emerges, this indicates structural change. Referring to his own definition of structural change, this can only be indirectly assessed. Sandell uses instruments such as self-rating personality inventories, observer rating scales, and other measures; the important difference is that in his research design Sandell makes repeated observations, exploring the consistency of the phenomenon of a stable, permanent, enduring "structural" change rather than just expecting it. Assuming that stabilization does not depend on the clinician or on the instrument being insensitive to change, or on the possibility that the patients respond to the basis of response sets such as social desirability, in order to please the analyst or therapist, Sandell was able to draw more reliable conclusions about what amount and kind of structural change had taken place.

In "On the contribution of the most recent research on language applied to psychoanalytic practice", the psychoanalyst Jorge Canestri links current findings of linguistics to psychoanalytic clinical practice. He presents some ideas on the use of language in psychoanalysis in the light of what psychoanalysis has learned from linguistics, neurolinguistics and the neurosciences in general during recent years. From a linguistic perspective, Canestri's starting point is to consider, following Chomsky, that the knowledge of language falls within the mind/brain human sys- 
tem (1-language). This makes linguistics a "science of nature" and opens the field to interdisciplinarity and, consequently, to a study of the elements that, in maturational stages and with specific modalities, contribute to the development of the child's "linguistic system". This system must be considered in close relation to the psychological development in order to analyze the quality of the representations and of the symbolizations that will inform the future mental life of the subject. Through the use of recently developed techniques of neuroimaging, neuroscience gives psychoanalysis the opportunity to revalue some of its own theories about the localizations of the linguistic functions. However even more interesting is the view that they offer us first the opportunity to investigate the acquisition of one's mother tongue in the light of the distinction between procedural and declarative memory, and second of differentiating, in terms of development, between the precocity of the auditory system and that of recognition and the relative delay of the phonic system. This is associated to precocity in understanding the meaning of communications which is certainly superior to children's effective linguistic realizations and actual lexical capacities. Canestri proposes that, when referring to the "linguistic system", we regard it as a complex semiotic system, inasmuch as in the case of infantile linguistic development, linguistic communication is inseparable from gestic and postural expression and from the use of multiple channels of communication, such as physical contact, glances, etc. The study of mother/environmentchild communication contributes, also in the adult age, to a better comprehension of the structure underlying the therapeutic interaction. In fact, an actual theory on linguistic acquisition and on the capacity of symbolization should be based on pragmatic criteria, i.e. on the real levels of affective and linguistic exchange and on the reciprocal affective monitoring between mother/environment-child. Furthermore, it should be taken into consideration that a large part of what takes place in the relationship between patient and psychoanalyst, in terms of prototypical reactions which repeat models of relationship with the primary objects, can be related to procedural or implicit memory. These two types of memory consist of two different registers of phenomena, i.e. multiple parallel channels for processing information that use different codes and modalities. Psychoanalysts being aware of these two types of memory are faced with the problem of continuously carrying out processes of translation, or of transformation, that link the incoming information to a common representation that can only be symbolic, that has to be shared with the patient, and that has to make use of words. The 
application of this knowledge to the psychoanalytic field leads Canestri to suggest an update of some of the criteria that up until now have oriented therapeutic action, and to propose a paradigm alternative to the classical one.

\section{REFERENCES}

Agassi, J. (1975). Science in Flux. Dordrecht: Reidel.

Baron-Cohen, S. (1995). Mindblindness: En Essay on Autism and Theory of Mind. Cambridge, Mass.: MIT Press.

Baron-Cohen, S., Tager-Flusberg, H. \& Cohen, D.J. (1993). Understanding Other Minds: Perspectives from Autism. Oxford: Oxford University Press.

Bieri, P., ed. (1993). Analytische Philosophie des Geistes. Bodenheim: Athenäum.

Blatt, S.J., Chevron, E.S., Quinlan, D.M., Schaffer, C.E., \& Wein, S.J. (1988). The assessment of qualitative and structural dimensions of object representations (revised edition). Unpublished research manual. New Haven, Yale University.

Blatt, S.J., D'Afflitti, J. P., \& Quinlan, D. M. (1976). Experiences of depression in normal young adults. Journal of Abnormal Psychology 85: 383-389.

Blatt, S.J., Levy, K.N., \& Shaver, P.R. (1998). Attachment styles and parental representations. Journal of Personality and Social Psychology 74: 407-419.

Blatt, S.J., Wein, S.J., Chevron, E., \& Quinlan, D.M. (1979). Parental representations and depression in normal young adults. Journal of Abnormal Psychology 88: $388-397$.

Block, N. (1995). On a confusion about a function of consciousness. The Behavioral and Brain Sciences, 18: 227-247; also in The Nature of Consciousness. Philosophical Debates, ed. N. Block, O. Flanagan. \& G. Güzeldere. Cambridge, Mass.: MIT Press 1997, pp. 375-415.

Block, N., Flanagan, O. \& Güzeldere, G., ed. (1997). The Nature of Consciousness. Philosophical Debates. Cambridge, Mass.: MIT Press.

Bott-Spillius, E. (1992). Clinical experiences of projective identification. In Clinical Lectures on Klein and Bion, ed. R. Anderson. London, New York: Routledge, pp. 59-73.

Brentano, F. (1874). Psychology from an Empirical Standpoint. Vol. 1. New Jersey: Humanities Press 1973.

Brentano, F. (1924). Über die Zukunft der Philosophie. Hamburg: Meiner 1968.

Chalmers, D. (1996). The Conscious Mind. Oxford: Oxford University Press.

Davidson, D. (1970). Mental events. In Essays on Actions and Events. Oxford: Clarendon Press 1980, pp. 207-225.

Davidson, D. (1984). First person authority. Subjective, Intersubjective, Objective. Oxford: Clarendon Press 2001, pp. 3-14.

Davidson, D. (1987). Knowing one's own mind. Subjective, Intersubjective, Objective. Oxford: Clarendon Press 2001, pp. 15-38.

Davidson, D. (1993). Reply to Peter Bieri. In Reflecting Davidson, ed. R. Stoecker. Berlin \& New York: De Gruyter, pp. 311-313. 
Diamond, D., Blatt, S. J., Stayner, D.A. \& Kaslow, N. (1991). Self-other differentiation of object representations. Unpublished research manual. New Haven, Yale University.

Dretske, F. (1995). Naturalizing the Mind. Cambridge: MIT Press.

Farah, M.J. (1994). Visual perception and visual awareness after brain damage: a tutorial overview. In Attention and Performance, ed. C. Umiltà \& M. Moscovitch. Cambridge, Mass.: MIT Press, pp. 37-75.

Farrell, B.A. (1950). Experience. Mind 59: 170-198.

Fisher, S. \& Greenberg, R.P. (1985). The Scientific Credibility of Freud's Theories and Therapy. New York: Columbia University Press.

Fisher, S. \& Greenberg, R.P. (1996). Freud Scientifically Reappraised: Testing the Theories and Therapy. New York: Wiley.

Fisher, S. \& Greenberg, R.P. (2002). Scientific tests of Freud's theories and therapy. In The Freud Encyclopedia. Theory, Therapy and Culture, ed. E. Erwin. New York, London: Routledge, pp. 509-514.

Flanagan, O. (1992). Consciousness Reconsidered. Cambridge, Mass: MIT Press.

Fodor, J. (1975). Special sciences, or the disunity of science as a working hypothesis. In The Language of the Thought. New York: Crowell, pp. 9-25.

Fonagy, P., Gergely, G., Jurist, E.L. \& Target, M. (2002). Affect Regulation, Mentalization, and the Development of the Self. New York: Other Press.

Fonagy, P., Target, M., Steele, H., \& Steele, M. (1998). Reflective-Functioning manual. $5^{\text {th }}$ edition. Unpublished research manual. London, University College London.

Foucault, M. (1967). Nietzsche, Freud, Marx. In Nietzsche. Cahiers de Royaumont. Paris: Minuit, pp. 183-192.

Freud, S. (1890a). Psychical (or mental) treatment. S.E. 7: 281-302.

Freud, S. (1891b) (1). On Aphasia. New York: International Universities Press 1953.

Freud, S. (1891b) (2). Zur Auffassung der Aphasien, ed. P. Vogel. Frankfurt am Main: Fischer 1992.

Freud, S. (1900a). The Interpretation of Dreams. S.E. 4.

Freud, S. (1905d). Three Essays on Sexuality. S.E. 7: 123-243

Freud, S. (1915e). The unconscious. S. E. 14: 159-207.

Freud, S. (1916-17a [1915-17]). Introductory Lectures on Psycho-Analysis. S.E. 16.

Freud, S. (1925d [1924]). An Autobiographical Study. S.E. 20: 7-70.

Freud, S. (1925e [1924]). The resistances to psycho-analysis. S.E. 19: 213-222.

Freud, S. (1926e). The Question of Lay Analysis. S.E. 20: 177-258.

Freud, S. (1933a [1932]). New Introductory Lectures on Psycho-Analysis. S.E. 22.

Freud, S.(1940a [1938]). An Outline of Psychoanalysis. S.E. 23: 139-207.

Freud, S. (1940b [1938]). Some elementary lessons in psycho-analysis. S.E. 23: 281-286.

Freud, S. (1950c [1895]). Project for a scientific psychology. S.E. 1: 295-397.

Freud, S. (1955e [1930]). Brief an Juliette Boutonier. Nachtragsband. Gesammelte Werke. Frankfurt am Main: Fischer 1987, pp. 671-672.

Freud, S. (1985). The Complete Letters of Sigmund Freud to Wilhelm Fließ 18871904, ed. J. M. Masson. Cambridge, Mass.: Harvard University Press. 
Freud, S. \& Ferenczi, S. (1993). The Correspondence of Sigmund Freud and Sándor Ferenczi 1908-1914. Vol. 1, ed. E. Brabant, E. Falzeder, \& P. GiampieriDeutsch. Cambridge, Mass.: Harvard University Press.

George, C., Kaplan, N. \& Main, M. (1996). Adult Attachment Interview. $3^{\text {rd }}$ edition. Unpublished research manual. Berkeley, Department of Psychology, University of California.

Giampieri-Deutsch, P. (1996). The influence of Ferenczi's ideas on contemporary standard technique. In Ferenczi's Turn in Psychoanalysis, ed. P. Rudnytsky, A. Bókay \& P. Giampieri-Deutsch. New York: New York University Press, pp. 224-247.

Giampieri-Deutsch, P. (1997). Die Psychoanalyse als Wissenschaft und andere Aspekte des Briefwechsels zwischen Sigmund Freud und Sándor Ferenczi. In Jenseits von Kunst, ed. P. Weibel. Wien: Passagen Verlag, pp. 621-626.

Giampieri-Deutsch, P. (1999). Freud und der gegenwärtige Stand der philosophischen Untersuchungen zur Theorie des Mentalen. Wiener Jahrbuch für Philosophie 31: 229-256.

Giampieri-Deutsch, P., ed. (2003a). Psychoanalyse im Dialog der Wissenschaften. Europäische Perspektiven. Vol. 1. Stuttgart: Kohlhammer.

Giampieri-Deutsch, P. (2003b). Die psychoanalytische Theorie des Mentalen und die analytische Philosophie des Geistes. In Psychoanalyse im Dialog der Wissenschaften. Europäische Perspektiven. Vol. 1, ed. P. Giampieri-Deutsch. Stuttgart: Kohlhammer, pp. 58-75.

Giampieri-Deutsch, P., ed. (2004a). Psychoanalyse im Dialog der Wissenschaften. Amerikanische Perspektiven. Vol. 2. Stuttgart: Kohlhammer.

Giampieri-Deutsch, P., ed. (2004b). Auswirkungen der Kooperation zwischen der analytischen Philosophie des Geistes und der Psychoanalyse auf die empirische psychoanalytische Forschung. Psychoanalyse im Dialog der Wissenschaften. Amerikanische Perspektiven. Vol. 2, ed. P. Giampieri-Deutsch. Stuttgart: Kohlhammer, pp. 80-91.

Grinberg, L. (1979). Countertransference and projective counteridentification. In Countertransference, ed. L. Epstein \& A.H. Feiner. New York \& London: Jason Aronson, pp. 169-191.

Grünbaum, A. (1984). The Foundations of Psychoanalysis. Berkeley: University of California Press.

Grünbaum, A. (1993). Validation in the Clinical Theory of Psychoanalysis. A Study in the Philosophy of Psychoanalysis. Psychological Issues Monograph 61. Madison: International Universities Press.

Grünbaum, A. (2002). Critique of psychoanalysis. In The Freud Encyclopedia. Theory, Therapy and Culture, ed. E. Erwin. New York, London: Routledge, pp. $117-136$.

Grünbaum, A., ed. (1991). Kritische Betrachtungen zur Psychoanalyse. Adolf Grünbaums , Grundlagen “ in der Diskussion. Berlin, New York: Springer.

Güzeldere, G. (1997). Introduction. The many faces of consciousness: a field guide. In The Nature of Consciousness. Philosophical Debates, ed. N. Block, O. Flanagan \& G. Güzeldere. Cambridge, Mass.: MIT Press, pp. 1-67.

Güzeldere, G., Flanagan, O. \& Hardcastle, V.G. (2000). The nature and function of 
consciousness: Lessons from blindsight. In The New Cognitive Neurosciences, ed. M. Gazzaniga. Cambridge, Mass.: MIT Press, pp. 1277-1284.

Habermas, J. (1968). Knowledge and Human Interest. Boston: Bacon Press 1971.

Jackson, F. (1982). Epiphenomenal qualia. American Philosophical Quarterly 32: 127-136.

Jackson, F. (1986). What Mary didn't know. Journal of Philosophy 83: 291-295

Klein, M. (1946). Notes on some schizoid mechanism. International Journal of Psycho-Analysis 27: 99-110.

Levin, F.M. (1991). Mapping the Mind. The Intersection of Psychoanalysis and Neuroscience. Hillsdale, London: The Analytic Press.

Levin, F.M. (2004). Psyche and Brain. The Biology of Talking Cures. Madison: International Universities Press.

Milner, B., Squire, L.R., \& Kandel, E.R. (1998). Cognitive neuroscience and the study of memory. Neuron 20: 445-468.

Nagel, E. (1959). Methodological issues in psychoanalytic theory. In Psychoanalysis, Scientific Method and Philosophy, ed. S. Hook. New York: New York University Press, pp. 38-56.

Nagel, T. (1974). What is it like to be a bat? In The Nature of Consciousness. Philosophical Debates, ed. N. Block, O. Flanagan \& G. Güzeldere. Cambridge, Mass.: MIT Press 1997, pp. 519-527.

Ogden, T.H. (1982). The analytic management and interpretation of projective identification. In Countertransference. Theory, Technique, Teaching. London: Karnac Book, pp. 21-46.

Popper, K. (1962). Conjectures and Refutations. New York: Basic Books.

Pribram, K.H., \& Gill M. (1976). Freud's Project Re-assessed. New York: Basic Books.

Ricœur, P. (1965). De l'interprétation. Essai sur Freud. Paris: Editions du Seuil.

Rubinstein, B.B. (1967). Explanation and mere description: A metascientific examination of certain aspects of the psychoanalytic theory of motivation. In Motives and Thought. Psychoanalytic Essays in Honor of David Rapaport. Psychological Issues Monograph 18-19, ed. R. Holt. New York: International Universities Press, pp. 18-78.

Schlick, M. (1925). Allgemeine Erkenntnislehre. Frankfurt am Main: Suhrkamp 1979.

Searle, J. (1992). The Rediscovery of the Mind. Cambridge, Mass.: MIT Press.

Shapiro, T. \& Emde R.N., ed. (1995). Research in Psychoanalysis: Process, Development, Outcome. Madison Connecticut: International Universities Press.

Shoemaker, S. (1993). The first-person perspective. In The Nature of Consciousness. Philosophical Debates, ed. N. Block, O. Flanagan \& G. Güzeldere. Cambridge, Mass.: MIT Press 1997, pp. 503-515.

Squire, L.R. \& Kandel E.R. (1999). Memory. From Mind to Molecules. New York: Scientific American Library.

Van Gulick, R. (1993). Understanding the phenomenal mind: are we all just armadillos? In Consciousness: Psychological and Philosophical Essays, ed. M. Davies \& G. Humphreys. Oxford: Blackwell, pp. 137-154.

Velmans, M., ed. (2000). Investigating Phenomenal Consciousness. Amsterdam, Philadelphia: John Benjamins Publishing Company. 
Waelder, R. (1962). Psychoanalysis, Scientific Method, and Philosophy. Journal of the American Psychoanalytic Association 10: 617-637.

Wittgenstein, L. (1953). Philosophical Investigations, ed. G.E.M. Anscombe, G.H. v. Wright \& R. Rhees. Oxford: Blackwell. 



\section{A. Psychoanalysis, Philosophy of Mind and Experimental Sciences: Research on Conscious and Unconscious Processes}


